\title{
Ultrasound Guided Supraclavicular Brachial Plexus Block with 0.5\% Bupivacaine and Additives: Case Series at Teaching Hospital Anuradhapura
}

\author{
Minura Hapugoda \\ Department of Anaesthesiology, Teaching Hospital Anuradhapura, Anuradhapura, Sri Lanka \\ Email: minura1988@gmail.com
}

How to cite this paper: Hapugoda, M. (2021) Ultrasound Guided Supraclavicular Brachial Plexus Block with 0.5\% Bupivacaine and Additives: Case Series at Teaching Hospital Anuradhapura. Open Journal of Anesthesiology, 11, 112-127. https://doi.org/10.4236/ojanes.2021.114011

Received: March 16, 2021

Accepted: April 24, 2021

Published: April 27, 2021

Copyright (อ 2021 by author(s) and Scientific Research Publishing Inc. This work is licensed under the Creative Commons Attribution International License (CC BY 4.0).

http://creativecommons.org/licenses/by/4.0/ (c) (i) Open Access

\begin{abstract}
Introduction: Supraclavicular block (SCB) is associated with excellent postoperative patient outcomes for upper limb surgeries. Bupivacainei is a longacting regional anaesthetic, efficacy of which is altered with the co-administration of additives. Aim: Aim of the study was to assess the efficacy of supraclavicular block with $0.5 \%$ bupivacaine compared to co-administration of additives and the associated complications. Method: Following ethical clearance and informed written consent, over 5 months from July 2020, 152 adult patients at Teaching Hospital Anuradhapura Sri Lanka undergoing upper limb surgeries were divided into 4 groups \& prospectively followed-up. All groups received $0.5 \%$ of Bupivacaine while additives $2 \%$ Lidocaine, $8.4 \%$ sodium bicarbonate \& $8 \mathrm{mg}$ Dexamethasone were added to the other 3 groups. Sensory and Motor block onset time, duration of post-block analgesia, acute and late complications and patient satisfaction were noted. Data was analysed using descriptive statistics \& ANOVA, using SPSS V.25. Results: Successful surgical anesthesia was achieved in all patients with 0 cases of long-term neurological complications with $94 \%$ patient satisfaction. The motor \& sensory block onset time \& post block analgesia duration respectively for Lidocaine $(9.74 \mathrm{~min}$, $9.74 \mathrm{~min} \& 7.07 \mathrm{~h}$ ), Bicarbonate (12.89 $\mathrm{min}, 16.32 \mathrm{~min} \& 12.09 \mathrm{~h}$ ), dexamethasone (19.34 $\mathrm{min}, 17.24 \mathrm{~min} \& 20.87 \mathrm{~h}$ ) \& Bupivacaine were $(20.39 \mathrm{~min}$, $18.42 \mathrm{~min} \& 13.15 \mathrm{~h})$. Conclusion: The differences between bupivacaine and lidocaine groups for sensory \& motor block onset times \& between Bupivacaine \& dexamethasone groups for post-block analgesia duration were statistically significant $(\mathrm{p}<0.001)$. Supraclavicular block has minimal associated complications \& additives Lidocaine shortens the onset of anaesthesia and the duration of analgesia while dexamethasone prolongs the duration of analgesia significantly.
\end{abstract}




\section{Keywords}

Supraclavicular, Lidocaine, Dexamethasone, Bicarbonate, Bupivacaine

\section{Introduction}

Kulenkampf [1] in 1911 first described the supraclavicular approach for the blockade of the brachial plexus and since then it has been a useful alternative to general anaesthesia for upper extremity surgery. Early on, the potential risk of pneumothorax when localizing the plexus [2] [3] lessened its popularity. Introduction of ultrasound and the peripheral nerve stimulator has improved and enhanced the safety of the procedure and Kapral [4] found no cases of pneumothorax, accidental puncture of vessels, as well as neurological damage with the use of ultrasound-guidance. The ultrasound-guided supraclavicular block is more rapidly performed and provides a more complete block than the block using anatomic landmarks and nerve-stimulator confirmation [5]. Ultrasound guided block uses lower volumes of local anaesthetic solution thus reducing the risk of adverse events and LA systemic toxicity [6].

Brachial plexus block is associated with excellent patient outcomes postoperatively for upper limb surgery, these benefits being; superior post-operative analgesia and recovery compared with that of general anaesthesia [7] [8] and opioid analgesia [9], and in providing similar quality of postoperative analgesia comparable to epidural analgesia [10]. Significantly better postoperative pain control was observed in the supraclavicular brachial plexus block with reduced nausea and vomiting [11] [12].

Bupivacaine is a long-acting regional anaesthetic. Inclusion of additives to Bupivacaine is aimed at hastening the onset and enhanced duration of blockade [13]. Popular additives being used are sodium bicarbonate [14], dexamethasone [15] and lidocaine [16]. In previous studies the addition of sodium bicarbonate [17] and lidocaine with adrenaline [18] was found to quicken the onset of action while some found no clinical advantage following the mixture of the above two [16] [19] [20]. Furthermore, addition of dexamethasone was found to prolong postoperative analgesia [21] [22] [23] while shortening the onset of motor and sensory block onset [23] [24].

The search for an ideal additive has led us to conduct this study at Teaching hospital Anuradhapura and contributes to the available data while assessing effectiveness, associated complications and patient satisfaction of ultrasound guided supraclavicular block. The aim of the study was to assess the efficacy of supraclavicular block with $0.5 \%$ bupivacaine compared to the co-administration of additives (Lidocaine with adrenaline, sodium bicarbonate and dexamethasone) in terms of sensory and motor block onset, duration of postoperative analgesia, associated complications and patient satisfaction with the overall supraclavicular block (SCB) and its outcome in patients undergoing upper extremity surgery at 
Teaching Hospital Anuradhapura Sri Lanka.

\section{Methods}

The ethical committee approval for the study was obtained from the Ethical Review Committee, Faculty of Medical and Allied Sciences, Rajarata University, Sri Lanka and institutional permission was acquired from the Teaching Hospital Anuradhapura, Sri Lanka. Patient's informed written consent was obtained before data collection. Information sheet and the consent form was given to the selected patients undergoing upper limb surgery on the prior day, during the preoperative anaesthetic assessment during the period of July $1^{\text {st }} 2020$ to $31^{\text {st }}$ December 2020. This was a prospective case series.

Inclusion criteria included patients aged 18 years and above with the American Society Anaesthesiologist (ASA) physical status of I or II undergoing upper limb surgery while the exclusion criteria included patients who refused to participate in the study, non-consenting patients, patients with significant coagulopathy, infection at the injection site, allergy to local anaesthetics, age less than 18 years, mental incapacity preventing informed consent, inability to cooperate during block placement or surgery, a body mass index more than $35 \mathrm{Kg} \cdot \mathrm{m}^{-2}$, pre-existing loss of force or sensation in the operative limb, pregnancy and ASA physical status IV \& V.

After informed written consent was obtained, patients were divided into 4 equal groups (38 patients in each group). PB group received $0.5 \%$ of Bupivacaine (Maximum $2 \mathrm{mg} / \mathrm{kg}$ ), BL group received $0.5 \%$ of Bupivacaine $+2 \%$ Lidocaine with adrenaline 1:80,000, with 1:1 volume ratio, $\mathrm{BD}$ group received $0.5 \%$ of $\mathrm{Bu}$ pivacaine $+8 \mathrm{mg}$ Dexamethasone $\& \mathrm{BB}$ group received $0.5 \%$ of Bupivacaine + $8.4 \%$ sodium bicarbonate at 200:1 volume ratio.

Demographic data was collected through an interviewer administered questionnaire [Appendix 1] which was validated through a pilot study, at the surgical theatre prior to nerve block.

Patients were subjected to fasting according to guidelines as per general anaesthesia (fasting for solids and semisolids for 6 hours prior to surgery, fasting for clear fluids for 2 hours prior to surgery).

On arrival to the operation theatre, standard monitoring, including, electrocardiography (ECG), non-invasive blood pressure (NIBP), and pulse oximetry were applied and baseline mean arterial pressure (MAP), heart rate (HR), and peripheral oxygen saturation $\left(\mathrm{SpO}_{2}\right)$ were monitored.

All the SCBs were performed by the investigator who was experienced with attending regional nerve block workshops and performing more than 100 brachial plexus blocks. All nerve blocks were performed adhering to the standard guidelines and following the universal precautions, using $50 \mathrm{~mm}, 22$ gauge (Stimuplex A insulated needle 30-degree bevel) insulated needles under strict aseptic conditions (the block area was cleaned with Betadine and 70\% isopropyl alcohol and draped). The block was performed while keeping the patient in the supine posi- 
tion comfortably with the head turned away from the surgical site. $2 \mathrm{ml}$ LA was injected into the skin using a $25-27$-gauge needle, $1 \mathrm{~cm}$ lateral to the Ultras Sound (US) high frequency transducer to decrease discomfort during needle insertion. Short axis, in-plane technique was used with a linear array US transducer to identify the anatomy for the block. Nerve stimulation if necessary, was used to identify the nerve $(0.5 \mathrm{~mA}, 0.1 \mathrm{mSec})$.

The anaesthetic solution used for the block consisted of, $0.5 \%$ bupivacaine or equal volumes of $0.5 \%$ bupivacaine and $2 \%$ lidocaine (+/- with 1:80,000 epinephrine) or $0.5 \%$ bupivacaine with $8 \mathrm{mg}$ Dexamethasone or $0.5 \%$ of Bupivacaine $+8.4 \%$ sodium bicarbonate at 200: 1 volume ratio and the administered anaesthetic solution volume was noted.

The duration between the first needle insertion and its removal at the end of the block was defined as the block execution time. An anaesthetist blinded to block allocation performed the time measurement.

Evaluation of sensory and motor block was performed in the specified nerve territories every 5 minutes over a 45 -min period beginning from the time the stimulating needle exited the patient by an anaesthetist blinded to block allocation, comparing the affected arm with the contralateral arm.

The motor block was gauged by examining the selective movements at the shoulder, elbow, wrist, and fingers, which corresponded to the motor components of the median, radial, ulnar, axillary and musculocutaneous nerve. Motor block was evaluated and scored as: No loss of force $(5 / 5)=$ no block; reduced force compared with the contralateral arm $(4-3 / 5)=$ partial block; incapacity to overcome gravity $(2-0 / 5)=$ complete block.

Sensory block was evaluated by comparing the cold sensation (elicited by ice) in the central sensory region of each nerve dermatome of the affected arm with the contralateral arm. Sensory block was evaluated as: normal sensation $=$ no block, reduced sensation $=$ partial block and total loss of cold sensation $=$ complete block.

If any surgical territory was not completely anesthetized at the time of surgery, the block was supplemented depending on the site. If the patient still experienced pain despite supplementation, anxiolytics and sedation will be used and failing which general anaesthesia was performed.

Block success was recorded with failure being defined as surgical anesthesia not present at 45 minutes, need for block supplementation after 45 minutes or conversion to general anesthesia during surgery.

Patients were subjected to full standard monitoring. The acute complications that were observed for, were signs of systemic local anaesthetic toxicity, accidental vascular puncture during procedure, accidental intravascular injection of anaesthetic solution, symptomatic pneumothorax (detected by a post-operative ultrasound scan of chest looking for loss of lung sliding, comet tail artifacts and barcode sign in M-mode), symptomatic hemi diaphragmatic paralysis due to phrenic nerve paralysis, post-operative nausea and vomiting (PONV) and any other com- 
plications (e.g. Horner's syndrome).

Patients were followed up during their hospital stay to determine the duration of post-block analgesia time which was defined as the duration from block onset time to when they first registered sensory inputs (e.g., pain/itching) by a trained pain management nurse blinded to block allocation.

Patients were asked about the discomfort or pain felt during the block procedure and the surgery through a numerical rating scale ( 0 to 10 with $0=$ no pain/ discomfort and $10=$ severe pain).

All the patients who received SCBs were followed up in four weeks for potential long-term neurologic complications and to assess the patient's satisfaction towards the supraclavicular nerve block via a telephone interview. Satisfaction was noted as to whether the patient was satisfied or unsatisfied with the overall SCB and its outcome and questioned about whether they would prefer to undergo surgery under same regional block procedure in the future or recommend it to others.

To detect potential neurological complications, patients were asked a standardized set of questions in relation to the operative limb by a trained pain management nurse blinded to block allocation; do you have any numbness? Do you have any tingling? Do you have any abnormal sensations? Do you have any pain? Do you have any weakness? If the patient complained of any neurological complications then further queries were made taking into account the anatomy relevant to the surgery and the peripheral nerve/plexus block. Symptoms that were immediately adjacent to the wound, consistent with normal tissue healing or the initial trauma were not considered relevant in terms of PNB being a causal factor. For patients with ambiguous symptoms or complaints, repeat contact was made in another 2 weeks. Triggers for referral to a neurologist were, new onset of motor and/or sensory deficit, non-resolving paraesthesia, pain and allodynia, or dysesthesia. If such neurological referral was done the patient was followed up for their neurological diagnosis/findings.

An audit was performed for the month of December 2019 to March 2020 at Teaching hospital Anuradhapura surgical operation theatres, which found upper limb surgeries accounted for $10.39 \%$ of all surgeries. Assuming a $95 \%$ confidence level and a margin of error of 5\%, calculated total sample size of 152 patients were divided in to 4 equal groups of 38 .

The quantitative data was screened, coded, and entered into the analytical computer software (SPSS v. 25) and analysed and descriptive statistics (mean (SD), frequency) calculated. The data obtained from the study was analyzed using one-way ANOVA with post hoc analysis with Games-Howell and Tukey's test, Pearson correlation and Chi-square test. $p$ value of $<0.05$ was considered statistically significant for all comparisons.

\section{Results}

A total of 152 ASA physical status I and II patients of both sexes, undergoing 
upper limb surgeries in Teaching hospital Anuradhapura who fulfilled the inclusion criteria participated in our study. All patients were allocated into 4 groups, 38 patients each.

Demographic data [Table 1] of the study population found that there was a male predominance $(67.8 \%)$. The age ranged between 18 to 80 years with the mean age being $44.12 \pm 14.70$ years and the mean BMI being $22.53 \pm 3.4 \mathrm{~kg} \cdot \mathrm{m}^{-2}$.

Forearm surgeries accounted for $73.03 \%$ of the surgeries performed under SCB and fracture Radius \pm Ulnar open reduction and internal fixation (ORIF) was the leading surgery performed at $44.7 \%$.

The mean supraclavicular block ( $\mathrm{SCB})$ procedure time was $4.57 \pm 0.66 \mathrm{mi}$ nutes while the mean surgical time was $1.33 \pm 0.73$ hours [Table 2].

There was a statistically significant difference between the time of onset of motor blockade $[F(3,78.65)=23.29, p<0.001]$ and sensory blockade $[F(3,148)$ $=13.153, p<0.001]$ for the anaesthetic solutions as determined by one-way ANOVA. The motor block onset time was shorter for the group BL $(M=9.74$, $S D=4.18)$ and $\mathrm{BB}(M=12.89, S D=5.88)$ compared to that of $\mathrm{PB}(M=20.39$, $S D=8.49)$. The sensory block onset time for the group BL $(M=7.04, S D=2.13)$ was shorter compared to that $\mathrm{PB}(M=18.42, S D=7.63)$. No statistically significant difference was found for the time of motor $(p=0.91)$ and sensory $(p=0.86)$ block onset of $\mathrm{BD}$ group and sensory $(p=0.51)$ block onset time for $\mathrm{BB}$ group compared to that of $\mathrm{PB}$ group.

The difference of the duration of post block analgesia time for the anaesthetic solutions were statistically significant $[F(3,78.97)=83.02, p<0.001]$ where the duration was prolonged in BD group $(M=20.54, S D=5.57)$ and shortened in BL group $(M=9.74, S D=4.18)$ compared to that of $\mathrm{PB}$ group $(M=13.09, S D=$ 2.54 ) while $\mathrm{BB}$ group had no statistically significant difference $(p=0.999)$.

There were no statistically significant correlations found with regard to the used $0.5 \%$ bupivacaine volume, $8.4 \%$ sodium bicarbonate volume, $2 \%$ lidocaine volume, concentration of Dexamethasone and the duration of onset of sensory and motor blockade as well as the duration of post block analgesia [Table 3].

Table 1. Demographic data.

\begin{tabular}{|c|c|c|c|c|c|}
\hline & All & $\mathrm{PB}$ group & BB group & BL group & $\mathrm{BD}$ group \\
\hline Age (years) & $44.12 \pm 14.7$ & $46.58 \pm 12.46$ & $45.24 \pm 15.79$ & $42.03 \pm 16.7$ & $42.63 \pm 13.59$ \\
\hline \multicolumn{6}{|l|}{ Sex } \\
\hline Male & $103(67.8 \%)$ & $30(78.9 \%)$ & $26(68.4 \%)$ & $26(68.4 \%)$ & $21(55.3 \%)$ \\
\hline Female & $49(32.2 \%)$ & $8(21.1 \%)$ & $12(31.6 \%)$ & $12(31.6 \%)$ & 17 (44.7\%) \\
\hline \multicolumn{6}{|c|}{$\mathrm{ASA}^{\dagger}$ classification } \\
\hline I & $113(74.3 \%)$ & $26(68.4 \%)$ & $30(78.9 \%)$ & $29(76.3 \%)$ & $28(73.7 \%)$ \\
\hline II & $39(25.7 \%)$ & $12(31.6 \%)$ & $8(21.1 \%)$ & $9(23.7 \%)$ & $10(26.3 \%)$ \\
\hline $\mathrm{BMI}\left(\mathrm{Kg} \cdot \mathrm{m}^{-2}\right)$ & $22.53 \pm 3.4$ & $22.86 \pm 3.61$ & $23.15 \pm 3.40$ & $21.07 \pm 3.01$ & $23.05 \pm 3.83$ \\
\hline
\end{tabular}

Data are described as mean \pm SD or number of patients (percentage \%); $\mathrm{ASA}^{\dagger}$ : American Society of Anaesthesiologist. 
Table 2. Procedure time, motor and sensory blockade onset time and duration of post-block analgesia.

\begin{tabular}{cccccc}
\hline & PB group & BB group & BL group & BD group & p-value \\
\hline Procedure time (minutes) & $4.78 \pm 0.59$ & $4.25 \pm 0.67$ & $4.56 \pm 0.69$ & $4.70 \pm 0.56$ & 0.002 \\
Surgery duration (hours) & $1.35 \pm 0.83$ & $1.43 \pm 0.51$ & $1.27 \pm 0.74$ & $1.24 \pm 0.79$ & 0.655 \\
Motor block onset (minutes) & $20.39 \pm 8.49$ & $12.89 \pm 5.88$ & $9.74 \pm 4.183$ & $19.34 \pm 8.94$ & $<0.001^{*}$ \\
Sensory block onset (minutes) & $18.42 \pm 7.63$ & $16.32 \pm 6.11$ & $9.74 \pm 5.19$ & $17.24 \pm 7.23$ & $<0.001^{*}$ \\
Post block analgesia (hours) & $13.15 \pm 2.9$ & $12.90 \pm 3.70$ & $7.07 \pm 2.22$ & $20.87 \pm 5.95<<0.001^{*}$ \\
\hline
\end{tabular}

Data are described as mean $\pm \mathrm{SD}$; ${ }^{*}$-value $<0.05$ is considered statistically significant.

Table 3. Average volumes and concentrations of anaesthetic solution and the correlations.

\begin{tabular}{ccccc}
\hline & $\begin{array}{c}0.5 \% \text { Bupivacaine } \\
\text { volume }(\mathrm{ml})\end{array}$ & $\begin{array}{c}\text { Sodium bicarbonate } \\
\text { volume }(\mathrm{ml})\end{array}$ & $\begin{array}{c}\text { Lidocaine }+ \\
\text { Adrenaline } \\
\text { volume }(\mathrm{ml})\end{array}$ & $\begin{array}{c}\text { Dexamethasone } \\
\text { concentration } \\
(\mathrm{mg} / \mathrm{ml})\end{array}$ \\
\hline Average volume/concentration & $12.23 \pm 2.90$ & $0.071 \pm 0.01$ & $7.86 \pm 2.22$ & $0.49 \pm 0.11$ \\
Motor block onset p-value & 0.121 & 0.218 & 0.915 & 0.045 \\
Sensory block onset p-value & 0.160 & 0.889 & 0.847 & 0.185 \\
Post block analgesia p-value & 0.172 & 0.758 & 0.059 & 0.419 \\
\hline
\end{tabular}

Data are described as mean $\pm \mathrm{SD} ;{ }^{* *} \mathrm{p}$-value $<0.01$ was considered statistically significant.

[Table 4] Pain and discomfort felt by the patient was monitored through a numerical rating scale (NRS). The average NRS score for pain felt during the block procedure $2.17 \pm 1.04$ and the average score for pain felt during the surgical procedure was $0.26 \pm 0.49$ and no significant difference was noted among groups.

With regard to the complications associated with supraclavicular block, there were no cases of local anaesthesia systemic toxicity, ultrasound evidence of pneumothorax or symptomatic hemi diaphragmatic paralysis due to phrenic nerve paralysis. There was 1 case $(0.65 \%)$ of accidental arterial puncture and 1 patient (0.6\%) with PONV who had over fasted for surgery (12 hours for solids).

With the follow up, one month after the supraclavicular block through the telephone interview there were no reported cases of neurological complications. One patient was lost to follow-up.

[Table 5] Patients were interviewed via telephone, to asses patient satisfaction and found $94 \%$ of patients were satisfied with the overall SCB and its outcome while $92.7 \%$ said that they would prefer to undergo surgery under same regional block procedure. The most common reason for poor satisfaction was pain felt during the block procedure and a strong negative correlation was found between numerical rating scale (NRS) score for block procedure and patient satisfaction $(\mathrm{r}(150)=-0.71, p<0.001)$. 
Table 4. The pain felt during the block procedure and surgery (numerical rating scaleNRS).

\begin{tabular}{cccccc}
\hline & PB group & BB group & BL group & BD group & p-value \\
\hline $\begin{array}{c}\text { Procedural } \\
\text { pain NRS }\end{array}$ & $2.50 \pm 0.95$ & $2.08 \pm 0.85$ & $2.21 \pm 1.21$ & $1.89 \pm 1.06$ & 0.076 \\
$\begin{array}{c}\text { Pain during } \\
\text { Surgery NRS }\end{array}$ & $0.13 \pm 0.34$ & $0.26 \pm 0.50$ & $0.32 \pm 0.62$ & $0.34 \pm 0.48$ & 0.121 \\
\hline
\end{tabular}

Data are described as mean $\pm \mathrm{SD}$; ${ }^{*}$-value $<0.05$ is considered statistically significant.

Table 5. Patient satisfaction.

\begin{tabular}{lcc}
\hline & Number of patients & Percentage \\
\hline Patient satisfaction & 142 & 94 \\
Satisfied & 9 & 6 \\
Unsatisfied & & \\
Will undergo surgery with same procedure/recommend & 140 & 92.7 \\
it to others? & 11 & 7.3 \\
$\quad$ Yes & & 90.9 \\
$\quad$ No & 10 & 9.1 \\
Reason for unsatisfaction/non recommendation & $1^{*}$ & \\
Pain/discomfort during block procedure & & \\
$\quad$ Paraesthesia lasting for 24 hrs & & \\
\hline
\end{tabular}

1 patient lost to follow-up; ${ }^{*}$ Paraesthesia resolved in 29.6 hours post procedure

\section{Discussion}

Supraclavicular brachial plexus block is widely used for upper limb surgeries and is used as an alternative to general anaesthesia. Bupivacaine is widely used for brachial plexus block due to its long duration of action. Various additives have been tried in combination with bupivacaine to shorten the onset of motor and sensory block and prolong the period of analgesia [13]. In our study we compared $0.5 \%$ bupivacaine with that of additives lidocaine with adrenaline, sodium bicarbonate and dexamethasone with regard to the duration of onset of motor and sensory block and the post block analgesia.

We used $8.4 \%$ sodium bicarbonate, $0.1 \mathrm{ml}$ per $20 \mathrm{ml}$ of plain bupivacaine (1:200 volume ratio) as recommended by prior studies [17] [25] as volumes greater than $0.1 \mathrm{ml}$ resulted in precipitation of bupivacaine base [26]. The results of our study where the motor block onset time was significantly shorter in alkalized $0.5 \%$ bupivacaine compared to that of $0.5 \%$ bupivacaine was supported by the findings of McMorland [17] who found elevation of the $\mathrm{pH}$ of the local anaesthetic significantly increased the speed of onset of action. McMorland [17] also found the duration of anaesthesia was also increased, this was in contrast to 
our findings where no significant prolongation was noted. The addition of sodium bicarbonate will raise the $\mathrm{pH}$ of a local anaesthetic solution. However, unlike other anaesthetic solutions, alkalization of bupivacaine to $\mathrm{pH}$ greater than 7.0 results in precipitation [27]. This inability to increase the $\mathrm{pH}$ of bupivacaine above 7.0 without precipitation limits the increase in the unionized form of the drug and might partially explain the lack of efficacy reported in our study where the onset of sensory blockade and the duration of post block analgesia did not show statistically significant difference to plain $0.5 \%$ bupivacaine. Some studies found that alkalinization of bupivacaine did not confer any advantage [19] [20].

In our study $0.5 \%$ bupivacaine was mixed with $2 \%$ lidocaine with adrenaline 1:80,000. These two medications are often used as a mixture to theoretically provide the longer action of bupivacaine and the faster onset of lidocaine and studies have examined safety, demonstrating no increased toxicity with mixtures of bupivacaine and lidocaine [28]. We found that the duration of onset of motor and sensory block was significantly shorter when compared to that of plain bupivacaine [18]. These results agree with those reported by Cuvillon et al. [29] who found a shortened onset of sensory and motor block time for femoral and sciatic nerve blocks using a mixture of bupivacaine and lidocaine with adrenaline.

Our findings were in contrast to the results that the mixture had no clinical advantage, with respect to onset of local blockade using lidocaine without adrenaline [30] [31] and the study by Collins et al using lidocaine with adrenaline [16].

We found that the duration of post-block analgesia was significantly shorter compared to that of plain bupivacaine which was in line with findings by some researchers [29]. A possible explanation for the shorter duration of post block analgesia time could be the reduction of bupivacaine concentration from $0.5 \%$ to $0.25 \%$ by $1: 1$ dilution, where Moura et al. [32] found time to first analgesic supplementation dose was longer for bupivacaine concentrations $\geq 0.3 \%$ (543.8 \pm $283.8 \mathrm{~min}$.), compared to $0.25 \%$ (391.3 $\pm 177.8 \mathrm{~min}$.).

Dexamethasone [33] a glucocorticoid, when used as an adjuvant to local anaesthetics in brachial plexus block has been found to prolong postoperative analgesia. Dexamethasone is a very potent and highly selective and long-acting glucocorticoid. The mechanism of prolonged regional anaesthesia and analgesia produced by corticosteroids is not fully understood. Steroids induce vasoconstriction, thus reduce local anaesthetic absorption. Furthermore, they increase the activity of inhibitory potassium channels on nociceptive C-fibre and inhibit synthesis and/or release of various inflammatory mediators. These three mechanisms [34] are known to prolong analgesia. This effect has been proposed to last up to 48 hours.

In the present study we observed that the addition of dexamethasone $(8 \mathrm{mg})$ to bupivacaine increased the duration of post block analgesia. Many studies reported the prolonged duration of sensory and motor block and time to first 
analgesic requirement when dexamethasone was used as an adjuvant with bupivacaine [21] [22] [23]. In some studies, the onset of sensory and motor effect was shortened [23] [24] which was contrary to our findings which found no significant shortening of motor and sensory block duration.

In our study we found $100 \%$ successful surgical anaesthesia following SCB. We found no cases of clinically symptomatic pneumothorax or ultrasound evidence of pneumothorax, symptomatic hemi diaphragmatic paresis, Horner's syndrome or local anaesthetic toxicity. Noted complications were a case of unintended vascular puncture and a case of PONV. There were no long term (lasting for $>4$ weeks) neurological complications. Perlas et al. [35] clinical outcome data from 510 consecutive patients who received an ultrasound-guided supraclavicular block for upper extremity surgery found transient sensory deficits in $(0.4 \%)$ and the frequency of prolonged ( $>4$ weeks) block related neurological complications in studies [36] [37] [38] [39] ranged from $0 \%$ to $0.2 \%$, which is comparable with the $0 \%$ in the current study.

\section{Conclusion}

In conclusion, ultrasound-guided supraclavicular block is associated with a high rate of successful surgical anaesthesia and a low rate of complications, specially short-term and long-term neurological complications. We have demonstrated that addition of lidocaine with adrenaline to $0.5 \%$ bupivacaine shortens the onset of motor and sensory block while reducing the post block analgesia time and with the addition of dexamethasone it prolongs the duration of post block analgesia with no effect on onset of block. Alkalinization of bupivacaine with sodium bicarbonate did not confer any advantage in reducing sensory onset nor prolonged post block analgesia time but motor block onset was shortened.

\section{Limitations}

In our case series, 152 patients were prospectively followed up 1 month post operatively and time duration was a limitation and a longer duration, 3 to 6 months follow up would be recommended. We practiced the alkalization of bupivacaine with $8.4 \%$ sodium bicarbonate $0.1 \mathrm{ml}$ per $20 \mathrm{ml}$ of plain bupivacaine as recommended but lacked ability to verify $\mathrm{pH}$ elevation.

\section{Conflicts of Interest}

The author declares no conflicts of interest regarding the publication of this paper.

\section{References}

[1] Kulenkampf, D. (1911) Anesthesia of the Brachial Plexus. Zentralblatt fur Chirurgie, 38, 1337-1350.

[2] Bridenbaugh, L.D. (1988) The Upper Extremity: Somatic Blockade. In: Cousins, M.J. and Bridenbaugh, P.O., Eds., Neural Blockade, Lippincott, Philadelphia, 387-416. 
[3] Wedel, D.J. (2000) Nerve Blocks. In: Miller, R.D., Ed., Anesthesia, Churchill Livingstone, New York, 1520-1548.

[4] Kapral, S., Krafft, P., Eibenberger, K., Fitzgerald, R., Gosch, M. and Weinstabl, C. (1994) Ultrasound-Guided Supraclavicular Approach for Regional Anesthesia of the Brachial Plexus. Anesthesia \& Analgesia, 78, 507-513. https://doi.org/10.1213/00000539-199403000-00016

[5] Williams, S., Chouinard, P., Arcand, G., Harris, P., Ruel, M., Boudreault, D. and Girard, F. (2003) Ultrasound Guidance Speeds Execution and Improves the Quality of Supraclavicular Block. Anesthesia \& Analgesia, 97, 1518-1523. https://doi.org/10.1213/01.ANE.0000086730.09173.CA

[6] Vazin, M., Jensen, K., Kristensen, D., Hjort, M., Tanggaard, K., Karmakar, M., Bendtsen, T. and Børglum, J. (2016) Low-Volume Brachial Plexus Block Providing Surgical Anesthesia for Distal Arm Surgery Comparing Supraclavicular, Infraclavicular, and Axillary Approach: A Randomized Observer Blind Trial. BioMed Research International, 2016, Article ID: 7094121. https://doi.org/10.1155/2016/7094121

[7] Hadzic, A., Arliss, J., Kerimoglu, B., Karaca, P.E., Yufa, M., Claudio, R.E., et al. (2004) A Comparison of Infraclavicular Nerve Block versus General Anesthesia for Hand and Wrist Day-Case Surgeries. Anesthesiology, 101, 127-132. https://doi.org/10.1097/00000542-200407000-00020

[8] Hadzic, A., Williams, B.A., Karaca, P.E., Hobeika, P., Unis, G., Dermksian, J., et al. (2005) For Outpatient Rotator Cuff Surgery, Nerve Block Anesthesia Provides Superior Same-Day Recovery over General Anesthesia. Anesthesiology, 102, 10011007. https://doi.org/10.1097/00000542-200505000-00020

[9] Richman, J.M., Liu, S.S., Courpas, G., Wong, R., Rowlingson, A.J., McGready, J., et al. (2006) Does Continuous Peripheral Nerve Block Provide Superior Pain Control to Opioids? A Meta-Analysis. Anesthesia \& Analgesia, 102, 248-257. https://doi.org/10.1213/01.ANE.0000181289.09675.7D

[10] Fowler, S.J., Symons, J., Sabato, S. and Myles, P.S. (2008) Epidural Analgesia Compared with Peripheral Nerve Blockade after Major Knee Surgery: A Systematic Review and Meta-Analysis of Randomized Trials. British Journal of Anaesthesia, 100, 154-164. https://doi.org/10.1093/bja/aem373

[11] Karaman, T., Karaman, S., Aşçı, M., Tapar, H., Şahin, A., Dogru, S. and Suren, M. (2019) Comparison of Ultrasound-Guided Supraclavicular and Interscalene Brachial Plexus Blocks in Postoperative Pain Management after Arthroscopic Shoulder Surgery. Pain Practice, 19, 196-203. https://doi.org/10.1111/papr.12733

[12] Auroy, Y., Benhamou, D., Bargues, L., Ecoffey, C., Falissard, B., Mercier, F.J., et al. (2002) Major Complications of Regional Anesthesia in France: The SOS Regional Anesthesia Hotline Service. Anesthesiology, 97, 1274-1280. https://doi.org/10.1097/00000542-200211000-00034

[13] Brummett, C.M. and Williams, B.A. (2011) Additives to Local Anesthetics for Peripheral Nerve Blockade. International Anesthesiology, 49, 104-116. https://doi.org/10.1097/AIA.0b013e31820e4a49

[14] Hilgier, M. (1985) Alkalinization of Bupivacaine for Brachial Plexus Block Regional Anesthesia. The Journal of Neural Blockade in Obstetrics, Surgery, \& Pain Control, 10, 59-61.

[15] Islam, S., Hossain, M. and Maruf, A. (2011) Effect of Addition of Dexamethasone to Local Anaesthetics in Supraclavicular Brachial Plexus Block. Journal of Armed Forces Medical College, Bangladesh, 7, 11-14. https://doi.org/10.3329/jafmc.v7i1.8619 
[16] Collins, J.B., Song, J. and Mahabir, R.C. (2013) Onset and Duration of Intradermal Mixtures of Bupivacaine and Lidocaine with Epinephrine. Plastic Surgery, 21, 5153. https://doi.org/10.1177/229255031302100112

[17] McMorland, G.H., Douglas, M.J., Jeffery, W.K., Ross, P.L.E., Axelson, J.E., Kim, J.H.K., et al. (1986) Effect of pH-Adjustment of Bupivacaine on Onset and Duration of Epidural Analgesia in Parturients. Canadian Anaesthetists' Society Journal, 33, 537-541. https://doi.org/10.1007/BF03014257

[18] Seow, L.T., Lips, F.J., Cousins, M.J. and Mather, L.E. (1982) Lidocaine and Bupivacaine Mixtures for Epidural Blockade. Anesthesiology, 56, 177-183. https://doi.org/10.1097/00000542-198203000-00004

[19] Bedder, M.D., Kozody, R. and Craig, D.B. (1988) Comparison of Bupivacaine and Alkalinized Bupivacaine in Brachial Plexus Anesthesia. Anesthesia \& Analgesia, 67, 48-52. https://doi.org/10.1213/00000539-198801000-00009

[20] Smith, S. and Ramamurthy, S. (1986) Effect of Sodium Bicarbonate on the Onset of Blockade by Bupivacaine. Regional Anaesthesia, 11, 48.

[21] Vieira, P.A., Pulai, I., Tsao, G.C., Manikantan, P., Keller, B. and Connelly, N.R. (2010) Dexamethasone with Bupivacaine Increases Duration of Analgesia in UltrasoundGuided Interscalene Brachial Plexus Blockade. European Journal of Anaesthesiology, 27, 285-288. https://doi.org/10.1097/EJA.0b013e3283350c38

[22] Nigam, R., Murthy, M., Kosam, D. and Kujur, A.R. (2015) Efficacy of Dexamethasone as an Adjuvant to Bupivacaine in Supraclavicular Brachial Plexus Block. Journal of Evolution of Medical and Dental Sciences, 4, 11157-11163. https://doi.org/10.14260/jemds/2015/1607

[23] Biradar, P.A., Kaimar, P. and Gopalakrishna, K. (2013) Effect of Dexamethasone Added to Lidocaine in Supraclavicular Brachial Plexus Block: A Prospective, Randomised, Double-Blind Study. Indian Journal of Anaesthesia, 57, 180-184. https://doi.org/10.4103/0019-5049.111850

[24] El-Baradey, G.F. and Elshmaa, N.S. (2014) The Efficacy of Adding Dexamethasone, Midazolam, or Epinephrine to 0.5\% Bupivacaine in Supraclavicular Brachial Plexus Block. Saudi Journal of Anaesthesia, 8, S78-S83.

https://doi.org/10.4103/1658-354X.144083

[25] McMorland, G.H., Douglas, M.J., Axelson, J.E., Kim, J.H.K., Blair, I., Blair, I., et al. (1988) The Effect of pH Adjustment of Bupi-Vacaine on Onset and Duration of Epidural Anaesthesia for Caesarean Section. Canadian Journal of Anaesthesia, 35, 457461. https://doi.org/10.1007/BF03026890

[26] de Jong, R.H. (1994) Local Anesthetics: From Cocaine to Xylocaine. Local Anesthetics, Mosby, St. Louis, 1-8.

[27] Redick, L.F. (1987) pH Adjustment of Chloroprocaine Solutions. Anesthesia \& Analgesia, 66, 286. https://doi.org/10.1213/00000539-198703000-00024

[28] de Jong, R.H. and Bonin, J.D. (1981) Mixtures of Local Anesthetics Are No More Toxic than the Parent Drugs. Anesthesiology, 54, 177-181. https://doi.org/10.1097/00000542-198103000-00001

[29] Cuvillon, P., Nouvellon, E., Ripart, J., Boyer, J.C., Dehour, L., Mahamat, A., L'hermite, J., Boisson, C., Vialles, N., Lefrant, J.Y. and de La Coussaye, J.E. (2009) A Comparison of the Pharmacodynamics and Pharmacokinetics of Bupivacaine, Ropivacaine (with Epinephrine) and Their Equal Volume Mixtures with Lidocaine Used for Femoral and Sciatic Nerve Blocks: A Double-Blind Randomized Study. Anesthesia \& Analgesia, 108, 641-649. https://doi.org/10.1213/ane.0b013e31819237f8

[30] Ribotsky, B.M., Berkowitz, K.D. and Montague, J.R. (1996) Local Anesthetics. Is 
There an Advantage to Mixing Solutions? Journal of the American Podiatric Medical Association, 86, 487-491. https://doi.org/10.7547/87507315-86-10-487

[31] Sweet, P.T., Magee, D.A. and Holland, A.J. (1982) Duration of Intradermal Anaesthesia with Mixtures of Bupivacaine and Lidocaine. Canadian Anaesthetists' Society Journal, 29, 481-483. https://doi.org/10.1007/BF03009413

[32] Moura, E.C., de Oliveira Honda, C.A., Bringel, R.C., Leal Pda, C., Filho Gde, J. and Sakata, R.K. (2016) Minimum Effective Concentration of Bupivacaine in Ultrasound-Guided Femoral Nerve Block after Arthroscopic Knee Meniscectomy: A Randomized, Double-Blind, Controlled Trial. Pain Physician, 19, E79-E86. https://doi.org/10.36076/ppj/2016.19.E79

[33] Noss, C., MacKenzie, L. and Kostash, M. (2014) Dexamethasone-A Promising Adjuvant in Brachial Plexus Anaesthesia? A Systematic Review. Journal of Anesthesia and Clinical Research, 5, Article No. 421.

https://doi.org/10.4172/2155-6148.1000421

[34] Marks, R., Barlow, J.W. and Funder, J.W. (1982) Steroid-Induced Vasoconstriction: Glucocorticoid Antagonist Studies. Journal of Clinical Endocrinology \& Metabolism, 54, 1075-1077. https://doi.org/10.1210/jcem-54-5-1075

[35] Perlas, A., Lobo, G., Lo, N., Brull, R., Chan, V.W.S. and Karkhanis, R. (2009) Ultrasound-Guided Supraclavicular Block: Outcome of 510 Consecutive Cases. Regional Anesthesia \& Pain Medicine, 34, 171-176. https://doi.org/10.1097/AAP.0b013e31819a3f81

[36] Fredrickson, M.J. and Kilfoyle, D.H. (2009) Neurological Complication Analysis of 1000 Ultrasound Guided Peripheral Nerve Blocks for Elective Orthopaedic Surgery: A Prospective study. Anaesthesia, 64, 836-844. https://doi.org/10.1111/j.1365-2044.2009.05938.x

[37] Capdevila, X., Pirat, P., Bringuier, S., Gaertner, E., Singelyn, F., Bernard, N., et al. (2005) Continuous Peripheral Nerve Blocks in Hospital Wards after Orthopedic Surgery: A Multicenter Prospective Analysis of the Quality of Postoperative Analgesia and Complications in 1,416 Patients. Anesthesiology, 103, 1035-1045. https://doi.org/10.1097/00000542-200511000-00018

[38] Watts, S.A. and Sharma, D.J. (2007) Long-Term Neurological Complications Associated with Surgery and Peripheral Nerve Blockade: Outcomes after 1065 Consecutive Blocks. Anaesthesia and Intensive Care, 35, 24-31. https://doi.org/10.1177/0310057X0703500103

[39] Wiegel, M., Gottschaldt, U., Hennebach, R., Hirschberg, T. and Reske, A. (2007) Complications and Adverse Effects Associated with Continuous Peripheral Nerve Blocks in Orthopedic Patients. Anesthesia \& Analgesia, 104, 1578-1582. https://doi.org/10.1213/01.ane.0000261260.69083.f3 


\section{Appendix 1}

\section{Questionnaire}

Code:

\begin{tabular}{|l|l|l|}
\hline \multicolumn{2}{|l|}{ Surgery Date: } & \multicolumn{2}{l|}{ Post op 1 month date: } \\
\hline \multicolumn{2}{|l|}{ Name: } & \multicolumn{2}{l|}{ Telephone no: } \\
\hline Gender $\quad \square \mathrm{M}$ & Age: & BMI: \\
\hline B.Wt $(\mathrm{kg}):$ & Height $(\mathrm{cm}):$ & \\
\hline
\end{tabular}

\begin{tabular}{|c|c|c|}
\hline \multicolumn{2}{|l|}{ Surgery: } & Ward: \\
\hline Anaesthetic solution: & & $\begin{array}{l}\square 0.5 \% \text { bupivacaine } \\
\square 0.5 \% \text { bupivacaine }+2 \% \text { lignocaine/+Adrenaline } \\
\square 8.4 \% \text { NaHCo } 0.1 \mathrm{ml} \\
\square \text { Dexamethasone } 8 \mathrm{mg}\end{array}$ \\
\hline Volume (ml): & 0.5\% Bupivacaine: & Other: \\
\hline
\end{tabular}

\section{Success of block}

\begin{tabular}{|c|c|c|c|c|}
\hline Motor block: & $\begin{array}{l}\square \text { Median } \\
\square \text { Musculocutaneous }\end{array}$ & \multicolumn{2}{|c|}{$\begin{array}{l}\square \text { Radial } \\
\square \text { Axillary }\end{array}$} & $\square$ Ulnar \\
\hline Success: & $\square$ Complete & \multicolumn{2}{|c|}{$\square$ Partial } & $\square$ No block \\
\hline \multicolumn{5}{|l|}{ Onset of motor block ( $\mathrm{min}$ ): } \\
\hline Sensory block: & $\begin{array}{l}\square \text { Median } \\
\square \text { Musculocutaneous } \\
\square \text { Lat cut. Forearm }\end{array}$ & \multicolumn{2}{|c|}{$\begin{array}{l}\square \text { Radial } \\
\square \text { Axillary }\end{array}$} & $\begin{array}{l}\square \text { Ulnar } \\
\square \text { Med cut. Forearm }\end{array}$ \\
\hline Success: & $\square$ Complete & \multicolumn{2}{|c|}{$\square$ Partial } & $\square$ No block \\
\hline \multicolumn{5}{|l|}{ Onset of sensory block ( $\mathrm{min})$ : } \\
\hline The block was supplemented & $\square$ Yes & \multicolumn{3}{|l|}{$\square$ No } \\
\hline \multicolumn{5}{|l|}{ If yes, Supplemented with } \\
\hline Sedation used: & $\square$ Yes & \multicolumn{3}{|l|}{$\square$ No } \\
\hline If yes, & $\square$ Midazolam & \multicolumn{2}{|c|}{$\square$ Fentanyl } & $\square$ Other \\
\hline GA performed: & $\square$ Yes & \multicolumn{2}{|l|}{$\square \mathrm{No}$} & \\
\hline Block success & $\square$ Yes & $\square$ No & Time: & $\mathrm{am} / \mathrm{pm}$ \\
\hline Tourniquet applied & $\square$ Yes & \multicolumn{2}{|l|}{$\square$ No } & \\
\hline
\end{tabular}




\begin{tabular}{|c|c|c|c|c|c|c|c|c|c|c|c|}
\hline Discomfort of tourniquet felt: & & & & & $\square$ & & & & & & \\
\hline \multirow{3}{*}{$\begin{array}{l}\text { Discomfort during PNB } \\
\text { procedure: (NRS) }\end{array}$} & \multicolumn{9}{|c|}{ No discomfort } & \multicolumn{2}{|c|}{ Severe pain } \\
\hline & 0 & & & 3 & 4 & 5 & 6 & 7 & 8 & & 10 \\
\hline & 0 & 0 & 0 & 0 & 0 & 0 & 0 & 0 & 0 & 0 & 0 \\
\hline \multirow{3}{*}{$\begin{array}{l}\text { Discomfort during surgery: } \\
\text { (NRS) }\end{array}$} & \multicolumn{9}{|c|}{ No discomfort } & \multicolumn{2}{|c|}{ Severe pain } \\
\hline & 0 & & & 3 & 4 & 5 & 6 & 7 & 8 & 9 & 10 \\
\hline & 0 & 0 & 0 & 0 & 0 & 0 & 0 & 0 & 0 & 0 & 0 \\
\hline \multicolumn{12}{|l|}{ Surgical time (hr:min) } \\
\hline $\begin{array}{l}\text { Duration of post-block } \\
\text { analgesia: (hr: } \mathrm{min} \text { ) }\end{array}$ & & & & & & & & & & & \\
\hline
\end{tabular}

\section{Complications}

\begin{tabular}{|l|ll|}
\hline Local anaesthesia systemic toxicity & $\square$ Yes & $\square$ No \\
\hline Arterial puncture & $\square$ Yes & $\square$ No \\
\hline Intraneural injection & $\square$ Yes & $\square$ No \\
\hline USS evidence of Pneumothorax & $\square$ Yes & $\square$ No \\
\hline Symptoms of Phrenic nerve paralysis (SOB) & $\square$ Yes & $\square$ No \\
\hline PONV & $\square$ Yes & $\square$ No \\
\hline Other: & & \\
\hline
\end{tabular}

\section{Satisfaction}

\begin{tabular}{|l|lc|}
\hline Are you satisfied with the PNB & $\square$ Yes & $\square$ No \\
\hline Will you recommend it to others & $\square$ Yes \\
\hline If not, why? & \\
\hline
\end{tabular}

\section{Neurological symptoms at 1 month with regard to arm}

\begin{tabular}{|l|ll|}
\hline Do you have any numbness? & $\square$ Yes & $\square$ No \\
\hline Do you have any tingling sensation? & $\square$ Yes & $\square$ No \\
\hline Do you have any abnormal sensations? & $\square$ Yes & $\square$ No \\
\hline Do you have any pain? & $\square$ Yes & $\square$ No \\
\hline Do you have any weakness? & $\square$ Yes & $\square$ No \\
\hline Persistence of symptoms after 6 wks. & $\square$ Yes \\
\hline Neurology referral done & $\square$ Yes & $\square$ No \\
\hline If yes, findings? & & \\
\hline
\end{tabular}


Motor Assessment

Musculocutaneous motor

Elbow flexion

Axillary motor

Abduction of arm beyond $150^{\circ}$

Ulnar motor

Thumb and wrist flexion

Supraclavicular nerves from cervical plexus (C3, C4)

Axillary Nerve

Superior lateral brachial cutaneous nerve $(\mathrm{C} 5, \mathrm{C} 6)$

\section{Radial Nerve}

Inferior lateral brachial cutaneous nerve (C5, C6)

Posterior antebrachial cutaneous nerve $(\mathrm{C} 6, \mathrm{C} 7)$

Intercostal brachial nerve (T2)

Medial brachial cutaneous nerve $(\mathrm{C} 8, \mathrm{~T} 1, \mathrm{~T} 2)$

Medial antebrachial cutaneous nerve (C5, C6)

Lateral antebrachial cutaneous nerve $(\mathrm{C} 5, \mathrm{C} 6)$

Radial Nerve

Superficial branch $(\mathrm{C} 6, \mathrm{C} 8)$

Median Nerve (C6, C8)

Ulnar Nerve (C8, T1)
Radial motor

Wrist and elbow extension

Median motor

Thumb and wrist flexion

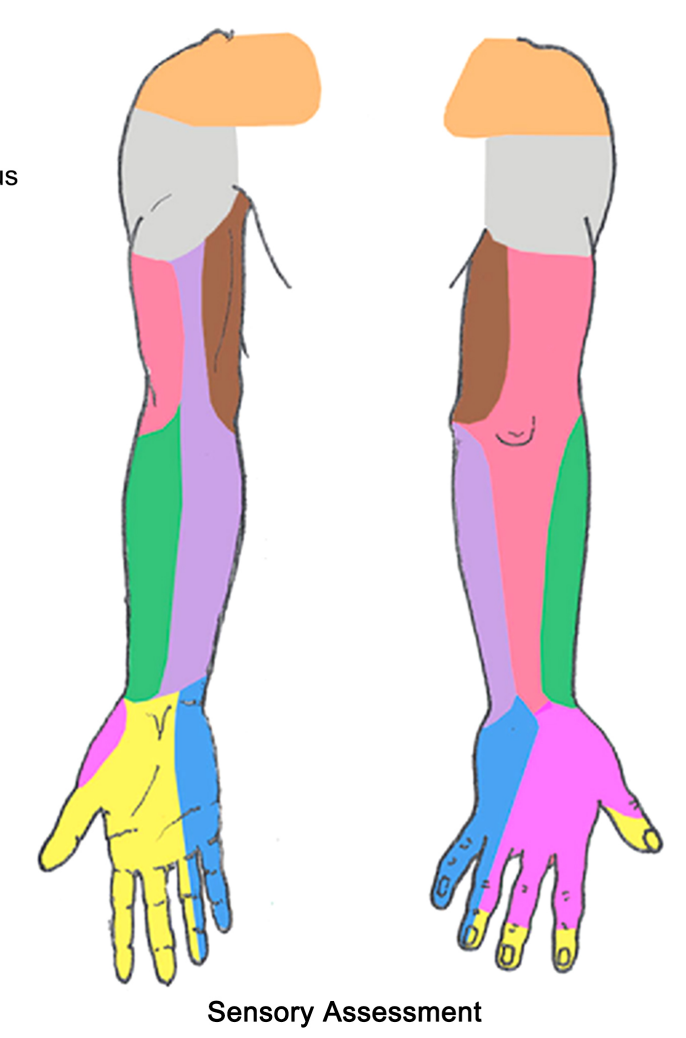

